\title{
In a pandemic, national and global interests
} \section{converge}

\author{
In ten contributions, mathematical modellers, public health officials, intellectual property experts and activists \\ explain how vaccine inequities continue to fuel the pandemic, and how multilateral cooperation can help.
}

$\mathrm{H}$ uman behaviour fuels pandemics, and it can help us to tame them. Expert scientific advice on behavioural interventions guided pandemic control policies throughout 2020 and 2021. Now, as evidence mounts for the causal links between vaccine inequities and the evolution of COVID-19, policy responses should likewise align with the scientific consensus and with our best moral principles.

A collection of articles in this issue of Nature Human Behaviour sends a clear message. Equitable and fair immunization of the world against COVID-19 is in the best interests of everyone, and it is within our reach.

A mathematical modelling study by Yang Ye and coauthors ${ }^{1}$ highlights the perils of inequitable vaccination, and exposes a fatal flaw in the logic of vaccine nationalism. The model indicates that the benefits of vaccine hoarding to high-income countries (HICs) will not last, as variants evolving in unvaccinated pockets will cause new surges of preventable deaths. Summarizing this research in a News \& Views piece ${ }^{2}$, Dan Yamin explains how multiple sources of disadvantage exacerbate the risks in low-resource settings. Vaccine sharing should be a priority for HICs, he argues, and there is initial evidence that the public supports it.

Global inequities in COVID-19 inoculations contradict the rational self-interest of HICs, but they are also immoral. Limited, life-saving resources such as vaccines are a global public good, regardless of who funded their development, writes bioethicist Keymanthri Moodley of Stellenbosch University ${ }^{3}$. The principles of ethical distributive justice, based on risks and needs, should apply globally, not only within individual countries.

Yet, vaccine-sharing initiatives — including COVAX - have so far been unable to close this ethical gap. Technological progress in the form of highly effective vaccines has prepared HICs for the future of living with COVID-19. But, as Samba Sow warns us from Mali, in poorly vaccinated parts of the world the future of 'living with COVID-19' is not an option ${ }^{4}$.

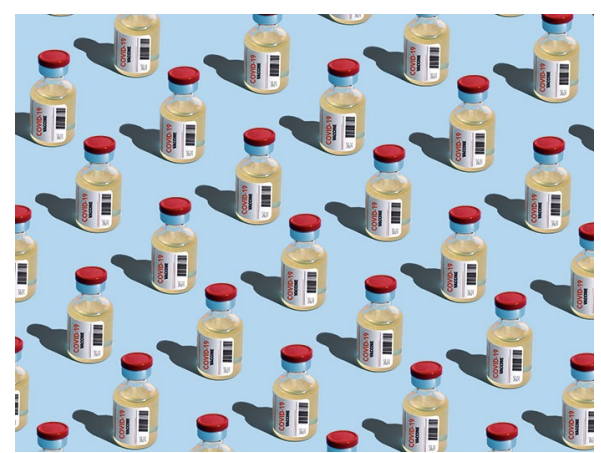

Credit: Yulia Reznikov / Moment / Getty

Populations who are still susceptible to severe disease, and precarious public health infrastructures, cannot just adapt to the virus.

The inequities we observe today may ultimately stem from pre-existing worldwide disparities. Indeed, as the director of UNAIDS Winnie Byanyima writes $^{5}$, we have seen similar dynamics unfold during the HIV/AIDS pandemic. Back then, pharmaceutical monopolies priced the Global South out of vital antiretroviral agents, causing millions of preventable deaths. The world needs to learn from these mistakes. Systemic disparities will continue fuelling global health crises until we uproot them, and this requires tight cooperation between the Global North and the Global South - a sentiment expressed by Ayoade Alakija in her World View ${ }^{6}$.

COVID-19 is a collective problem, and one that self-interested actions will not solve. Unilateral travel bans, such as the ones imposed after the emergence of Omicron, reflect such individualistic interests and hinder cooperation, argues Philani Mthembu of South Africa's Institute

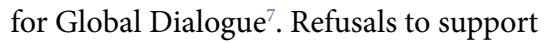
intellectual property waivers and mRNA technology transfers lock the Global South out of producing vaccines locally, again narrowly focusing on individual benefit. Although some believe that rapid technological progress would not be possible without the incentives provided by restrictive intellectual property systems, innovation alone will not end COVID19, Tahir Amin writes ${ }^{8}$. Fixating on technological advancements will not get us far - we also need to rewire ourselves to use them for the collective good.

Rewiring ourselves for collective action can take many forms. As Winnie Byanyima writes, breaking pharmaceutical monopolies helped to address the HIV/AIDS pandemic in the early $2000 \mathrm{~s}^{4}$ and similar actions can help now. Achal Prabhala and Alain Alsalhani's Correspondence ${ }^{9}$ reveals that over 100 manufacturers in the Global South already have the capacity to produce mRNA vaccines, a fact that current developers will need to acknowledge. And COVAX, which has not been able to achieve its initial goals, is capable of delivering vaccines at scale. To fully succeed, however, it needs sufficient donations of suitable vaccine stock, more timely financing and ancillary support, GAVI's deputy CEO Anuradha Gupta writes in a World View ${ }^{10}$.

The worst of COVID-19 will end, but there will be other health crises. Will we then have to negotiate a new COVAX Facility from scratch? Will we need to debate intellectual property rights waivers anew? The world needs cooperation-enforcing mechanisms that can match the rapid pace of viral spread and evolution - a prenegotiated framework for the distribution of vaccines, tools and intellectual know-how.

Multilateral agreements are hard to reach when collective, individual and commercial interests do not align, and when the fast-moving pandemic cycle creates further incentives to prioritize narrow interests. Negotiations on the CFC-banning accord in the lead-up to the Montreal Agreement took years to complete $^{11}$, and binding climate-action treaties are even harder to reach. As world leaders commit to negotiations of a pandemic-response pact laying the groundwork for more cooperative mechanisms in future health crises ${ }^{12}$, they should remember that individual and collective interest in pandemic management are one and the same ${ }^{1}$. 
Published online: 31 January 2022

https://doi.org/10.1038/s41562-022-01309-7

References

1. Ye, Y. et al. Nat. Hum. Behav. https://doi.org/10.1038/s41562-02201289-8 (2022).

2. Yamin, D. Nat. Hum. Behav. https://doi.org/10.1038/s41562-02201297-8 (2022)
3. Moodley, K. Nat. Hum. Behav. https://doi.org/10.1038/s41562022-01295-w (2022)

4. Sow, S. Nat. Hum. Behav. https://doi.org/10.1038/s41562-02201296-9 (2022).

5. Byanyima, W. Nat. Hum. Behav. https://doi.org/10.1038/s41562022-01307-9 (2022).

6. Alakija, A. Nat. Hum. Behav. https://doi.org/10.1038/s41562-022 01305-x (2022).

7. Mthembu, P. Nat. Hum. Behav. https://doi.org/10.1038/s41562 022-01300-2 (2022).
8. Amin, T. Nat. Hum. Behav. https://doi.org/10.1038/s41562022-01298-7 (2022).

9. Prabhala, A. \& Alsalhani, A. Nat. Hum. Behav. https://doi.org/ 10.1038/s41562-022-01304-y (2022).

10. Gupta, A. Nat. Hum. Behav. https://doi.org/10.1038/s41562-02201308-8 (2022).

11. Morrisette, P. M. Nat. Resour. J. 29, 793-820 (1989).

12. Maxmen, A. Nature, https://doi.org/10.1038/d41586-021-03596-y (December 2021). 